\title{
LG G5 Advertisement Focused on Visual and Verbal Image
}

\section{Lee Seung Hwan}

English Department, Faculty of Languages and Literature, Petra Christian University, Siwalankerto 121-131, Surabaya 60236, INDONESIA

E-mail: m11411041@john.petra.ac.id

\begin{abstract}
I want to analyze LG G5 advertisement, because LG G5 is different from other companies' mobile phones. When LG G5 was released newly, LG G5 had special functions, unique designs, and several additional device and modular types. Therefore, LG G5 advertisement is worth researching. This research attempts to discover the perceived meaning in G5's advertisement of LG. At the elaborations of research problem, two research questions arise as follows (1) how meaning is in the advertisement created through verbal expression (2) how meaning is in the advertisement supported by visual expression. The theories used are semiotics, signification, denotation and connotation. Methods are descriptive qualitative. The findings imply that LG G5 is a symbol of happiness, enjoyment, and an icon of fancy and modernity by the verbal expression. In addition, this shows LG G5's brand image as LG is technology innovation company, as well as a company that support happiness in people's life by verbal and non-verbal expression.
\end{abstract}

Keywords: Visual and verbal images, life, good, happiness, phone, modular type

\section{INTRODUCTION}

The importance of advertising in marketing is highly emphasized by Amstell (1969, p28), who states that advertising is designed to build the reputation of the companies that use the advertising, and to give some information about the products of those companies. This way, advertising is used for building the confidence of the consumer who buy those products. In so doing, through advertisement, the companies want to create a picture of their products in the mind of the consumers in memorable and understandable phrase. That is why advertisement must be able to create consumers' feeling of affinity and to capture the consumers' attention. A striking impression as the effect of advertisement is important, because the impression of the consumers have can increase the consumers' interest, which leads the consumers' interest to buy the products advertised. This research wants to discover the perceived meaning in G5's advertisement of LG. At the elaborations of research problems, these are the two research questions: 1. How is meaning in the advertisement created through verbal expression? 2. How is meaning in the advertisement supported by visual expression?

"Denotation and connotation operate at the level of signified" (Chandler, 2007, p. 137). According the sentences above, we can assume that denotation and connotation constructs essential concepts in terms of meaning or signified. A meaning always includes both denotation and connotation in the sense that there must be an individual perception regarding any sign. The first layer of signification is called denotation which consists of signifier and signified. As described in Semiotic the Basic by Chandler, 'denotation' tends to be described as the definitional, literal, obvious or common-sense meaning of a sign. Denotative meaning is the direct meaning or what the dictionary would like to interpret about something. The next layer of signification is connotation. Connotation refers to personal interpretation or socio cultural associations Therefore, the connotative meaning can be differed by different people who have another back ground or personal interpretation regarding to their class, age, gender or education 
Hwan: LG G5 Advertisement Focused on Visual and Verbal Image

background. Simply, denotation is referred to something visible which we can see from our eyes, and connotation is something personally or individually meant by personality or society.

\section{METHOD}

In this study, the writer collected the data from a downloaded advertisement and the interpretation meanings by both the writer and the respondents on online. The source of data in this study is the LG Inc. There are two advertisement videos from LG's the newest mobile; G5 which has striking impression and contained signification. The writer only chose G5, the newest mobile from LG because there are so many other products from LG such as G4, G3 or G Cat. The writer is going to collect the data from the video of LG G5 advertisement from LG's official YouTube channel.

Here, the writer analyzed the visual expression in G5 advertisements to understand its meaning by referring to the theories which I mentioned before and find the association with other things that would help the writer in understanding the meaning in the advertisement. In the advertisement, there are few verbal expressions but there are not so many verbal expressions compared with visual expression. Hence, the writer focused on the visual expression in the advertisement first. See you statement of the problem. The focus should be the verbal expression.

\section{FINDINGS AND DISCUSSION}

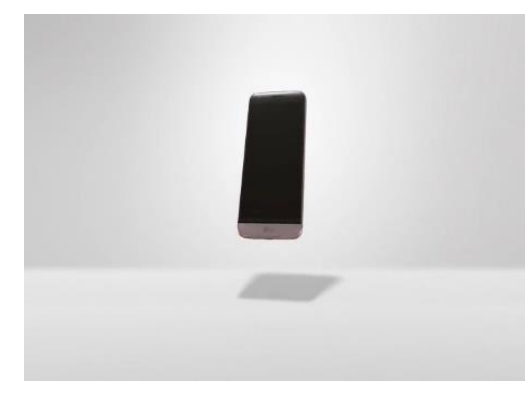

The video clip starts with indicating the shape of LG G5 mobile phone with its 360 degrees turning around. As LG G5 is a designed phone with modular type, under the main module of LG G5, there is sub-module which is battery in the screenshots as I attached above. In the battery, the sentence "Life is good when you play more" is written on the center with yellow color of background of battery. Based of Oxford Advanced Learner's Dictionary Online, the word "Life" means the ability to breathe or which people, animals and plants have before they die and which objects do not have. The word "Life" from the sentence has a connection with an influence and selling purpose of LG G5 mobile phone toward the customers that the customers' life can be better or nicer by using LG G5 mobile phone. Based on the research from BournCreative.com, the color of yellow means happiness, positivity, warmth, cheerfulness, increased mental activity, increased muscle energy ("BournCreative.com, Color Meaning: Meaning of the color Yellow, 2011). So, the visual expression of the opening is the color of yellow and it connotatively supports the sentence, such as the slogan of LG G5. 


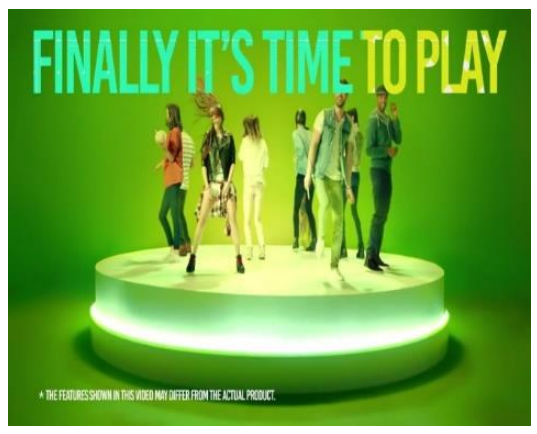

After showing the images of LG G5, several characterized people are dancing and jumping together on the stage with the sentence "Finally it's time to play LG G5 \& Friends", as can be seen from the image above. The denotative meaning of 'Finally' is that there is no such product like LG G5 before. The word 'Finally' is also indicated with several colors and font sizes. Therefore, we can see how LG focuses on the word 'finally' in order to transfer the meaning to their customers LG G5 is the phone that there is no such a product like this before in the verbal expression. Therefore, the denotative meaning of the sentence is "At last, we can enjoy with LG". The phrase 'It's time' is interpreted with the visual expression, actors and actresses in the advertisement dance and jump together on the stage. In visual expression, actors and actresses are metaphor of the LG G5 customers, who are cool and pretty like the people in the advertisement. They also always smile. Therefore, it describes that customers who buy LG G5 would be very satisfied with the product. In conclusion, the connotative meaning of this scene is that "LG G5 mobile phone is the phone which customers are waiting to buy".

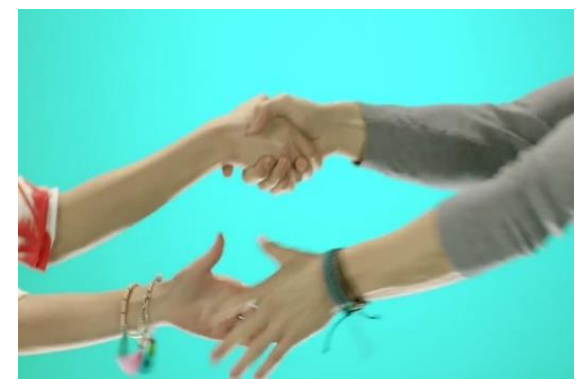

The first function of LG G5 to analysis in terms of verbal and visual expressions is Quick Swap Battery Design. In the scenes, at the beginning, one woman and one man do clapping game gestures quickly in several motions, as can be seen from the picture above. In the middle, they change and swap the battery of LG G5 as fast as how fast they did clapping game gestures before. Therefore, the woman can take her phone call before the man does last clapping motion. This scene is used to describe how quickly the battery of LG G5 can be changed such as the speed of people do clapping game. As mention in Oxford Dictionary online, the word "Quick" means done with speed or moving or doing something fast (Oxford Advanced Learner's Dictionary Online). That is why the word here 'Quick Swap' connotatively describes LG G5 mobile phone has a function that can change battery much quicker compared with other mobile phones that have no function of changing batter with quick swapping. In conclusion, the meaning of the first function of LG G5, Quick Swap Battery Design in terms of connotative meaning is that swapping LG G5's battery is a very moment like the customer can change LG G5's battery in a second in reality. 


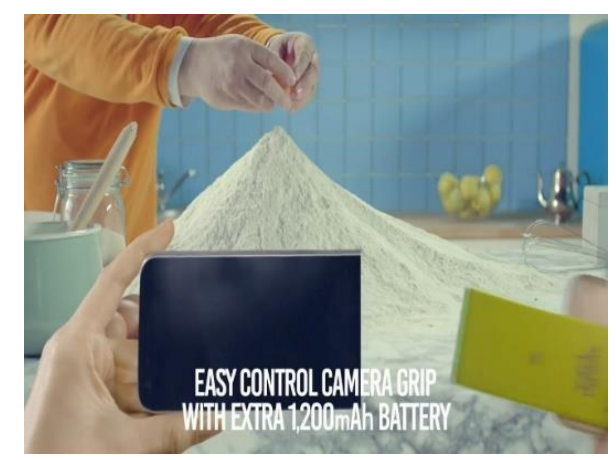

The second function of LG G5 is that Cam Plus function. There is quantity of flour on the floor and a man who wears orange color sweater breaks an egg from the top of flour tower. Besides that, another guy is taking a video in front of the tower of flour. Meanwhile, the flour tower becomes white mountain, and the egg becomes a man who is riding snow ski in a caption on the right side. As mentioned in Dictionary.com, the word "plus" is defined as something with addition of or more by than the usual one. The object "egg" is also defined as the roundish reproductive body produced by the female animals or human. From the word "plus" and "egg", LG G5 is signified as a thing that has addition or more about compared with other mobile phones. Thus, with the function of LG G5's Cam Plus, a reproductive creature can become a developed creature, like the man who is riding a ski.

There is another sentence below the clip, which is "Easy Control Camera Grip with Extra 1,200mAh Battery" which describes the function of the sentence, "Easy Control Camera Grip". Based on Oxford Advanced Learner's Dictionary, "Easy" is described as not difficult; done or obtained without a lot of effort or problems. The man in the video clip is reading a newspaper and eating ramen while he is riding a ski with jumping up. Normal people rarely do eating or reading something while they do something like extreme sports or they cannot do that physically in fact. Therefore, these visual expressions and verbal expressions are described like activities which people usually cannot do in a tough situation can be activated easily with the function of Easy Control Camera Grip from LG G5. In conclusion, the denotative meaning of these expressions is the Cam Plus module makes easier to control camera function and adds battery capacity. And the connotative meaning of these expressions is that LG G5 users can use its camera much easier or convenient than other cameras with the function of LG G5.

The third function of LG G5 is that "HI-FI Plus with B\&O Play". The first scene is described as showing the working situation of usual office with some tired faces of usual appearance office guys. After that, the module of LG G5 is exchanged with another module, which has function of HI-FI Plus, and then half of the scene is also exchanged with club background which is suitable with the worker's pose and situation from the original working background. The word "HI-FI" is defined as a term used by listeners, audiophiles and home audio enthusiasts to refer to high-quality reproduction of sound. The first scene is described as just normal HI-FI. Even though the works look tired or not so enthusiastic in order to work in their place, they anyway produce the conclusion from their work in the end with the best way or solution made by the effort of their work. The word "plus" is defined as something with addition of or more by than the usual one based on Dictionary.com. Therefore, the word "HI-FI Plus" has a relation with the scene addition of club background on below the scene in terms of visual and verbal expressions. By adding the word "Plus" and the addition scene of club background, the ambience of the office and the expressions of the works there would become much more enjoyable and enthusiastic compared with the previous one, just normal working place and normal working ambience. Also, there is a song whose title is sax on the Dancefloor by Polar Front which does not really existent song and artist. Polar Front is defined as the boundary, at this boundary, a sharp gradient in temperature occurs between these two air masses, each at very 
different temperatures. The Polar Front, which doesn't really existent artist, is descried as LG G5 device, because like the definition of Polar Front, the boundary is made by two air masses, one air is described as main frame device of LG G5 and the other air is described as the module which has a function of HI-FI Plus. When those two devices are combined together, the place becomes very enjoyable and enthusiastic like the scene office guys dance like crazy after they are edited with club back ground (HI-FI Plus module) like the song title, Sax on the Dancefloor. In conclusion, the denotative meaning of these scenes is the audio dac has a High Fidelity function which is developed by cooperating with the brand, $\mathrm{B} \& \mathrm{O}$ and the connotative meaning of these scenes is LG G5 has a portable audio module which is composed only for better audio quality and cooperates with well-known audio device brand for better performance which can make people very enjoyable and enthusiastic even though they were bored.

\section{CONCLUSION}

In short, the verbal expressions imply that LG G5 is a symbol of happiness, enjoyment as well as an icon of fancy and modern life. Both the verbal and non-verbal expressions highlight LG G5's brand image as innovative company, as well as a company that support happiness in people's life.

\section{REFERENCES}

Chandler, D. (2007). Semiotics the basics (2nd ed). London: Routledge.

Eco, U. (1976). A theory of semiotics. Bloomington, IN: Indiana University Press. London: Macmillan

Hall, S. (1973). 'Encoding/Decoding', in Centre for Contemporary Cultural Studies (ed.). London: Hutchinson.

Knowles, M., \& Moon, R. (2004). Introducing metaphor. Routledge.

Bendixen, M.T. (1993) Advertising effects and effectiveness, European Journal of Marketing, 27(10), pp. 19-32.

Pitta, D.A. and Prevel Katsanis, L. (1995) Understanding brand equity for successful brand extension, Journal of Consumer Marketing, 12(4), pp. 51-64. 